Original Article

\title{
The effects of spinal support device on pain and extensibility of the hamstrings in patients with non-specific low back pain
}

\author{
Eun Tae Jeon, MSc, PT ${ }^{1) a}$, Jin-Hwa Jung, PhD, OT ${ }^{2) a}$, Jong Hoon Moon, MSc, OT ${ }^{3)}$, \\ Kyoung-Sim Jung, PhD, PT ${ }^{2}$, Young SiK Won, MS, OT ${ }^{4}$, Sung-Jin KIM, MS, PT $^{5}$, \\ Suk-Chan Hahm, PhD, $\left.\mathrm{PT}^{6}\right)^{*}$, Hwi-Young Cho, PhD, $\mathrm{PT}^{7)^{*}}$ \\ 1) Department of Physical Therapy, Graduate School, Gachon University, Republic of Korea \\ 2) Department of Occupational Therapy, Semyung University, Republic of Korea \\ 3) Department of Occupational Therapy, Graduate School, Gachon University, Republic of Korea \\ 4) Department of Occupational Therapy, Shinsung University, Republic of Korea \\ 5) Department of Physical Therapy, Sahmyook University, Republic of Korea \\ 6) Department of Rehabilitation Standard and Policy, National Rehabilitation Research Institute, \\ National Rehabilitation Center: 58 Samgaksan-ro, Gangbuk-gu, Seoul 01022, Republic of Korea \\ 7) Department of Physical Therapy, College of Health Science, Gachon University: 191 \\ Hambangmoe-ro, Yeonsu-gu, Incheon 406-799, Republic of Korea
}

\begin{abstract}
Purpose] The objective of this study was to investigate the effects of spinal support device (SSD) on pain and hamstring extensibility in patients with non-specific low back pain (NSLBP). [Subjects and Methods] 20 patients with NSLBP were recruited and randomly assigned to either the SSD group or the control group. In the SSD group, SSD was applied; in the control group, bed rest in supine position was performed. Both groups underwent treatment $20 \mathrm{~min} /$ day, 3 times a week, for a duration of 4 weeks. To assess the hamstring extensibility, sit and reach test (SRT) was performed. To assess pain pressure threshold (PPT) of the sacroiliac joint, a pressure algometer was used. Visual analog scale (VAS) was used to quantify pain. [Results] The SSD group showed a significant improvement in sacroiliac joint pain with increased VAS, and the control group showed a significantly increased VAS after intervention. In the SSD group, VAS was significantly increased, but SRT was not changed compared with the control group. [Conclusion] These results demonstrated that an application of SSD effectively attenuates low back pain. Therefore, SSD may be a suitable intervention for pain control in patients with NSLBP.

Key words: Hamstring, Nonspecific low back pain, Spinal support device
\end{abstract}

(This article was submitted Mar. 20, 2017, and was accepted May 9, 2017)

\section{INTRODUCTION}

Non-specific low back pain (NSLBP) is a common health problem worldwide, and most people of all ages may suffer from $\mathrm{NSLBP}^{1}$. NSLBP is associated with decreased range of motion (ROM), muscle strength, and flexibility of the lumbar and hip joints ${ }^{2}$, which can result in tension soreness and stiffness of the lumbar and hip joints. These changes by NSLBP may lead to a functional limitation in daily-living activities and a decrease in social activity ${ }^{3)}$.

It is commonly well established that people with NSLBP experience decreased hamstring extensibility ${ }^{4)}$. Decreased

\footnotetext{
*Corresponding authors. Suk-Chan Hahm (E-mail: schahm@korea.kr); Hwi-Young Cho (E-mail: hwiyoung@gachon.ac.kr)

aThese two authors contributed equally to this study as co-first authors.

*These authors contributed equally to this work as corresponding authors.

(C2017 The Society of Physical Therapy Science. Published by IPEC Inc.
}

(c) (i) $\odot$ This is an open-access article distributed under the terms of the Creative Commons Attribution Non-Commercial No Derivacc) 
hamstring extensibility increases posterior tilting of the pelvis, decreasing lumbar lordosis, which may result in a flat back posture. Flat back posture has been known to be highly correlated with low back pain ${ }^{5}$.

Hagen et al. has reported that bed rest with an appropriate position can alleviate back pain ${ }^{6}$. Nachemson et al. has also shown that appropriate position in supine decreased intradiscal pressures in patients with NSLBP ${ }^{7}$. However, few previous studies investigated the effects of lumbar curvature using orthosis on non-specific low back pain ${ }^{8,9)}$. Thus, more studies on the effect of orthosis, which corrects lumbar curvature on pain and hamstring extensibility in patients with non-specific low back pain are necessary.

Spinal support device (SSD) was developed to correct abnormal spinal curvatures. However, the effect of orthosis on NSLBP has yet to be demonstrated. Therefore, the aim of this study was to demonstrate the effect of SSD on pain and hamstring extensibility in patients with NSLBP.

\section{SUBJECTS AND METHODS}

20 people with NSLBP were recruited. The inclusion criteria were as follows: having NSLBP for at least 1 month prior to participation, fingertip-to-floor distance $\geq 0 \mathrm{~cm}$, passive straight leg raise of $\geq 70$ degrees, visual analog scale of $\geq 3$, and touching of knee joint and chest in passive hip-flexion test. The exclusion criteria were as follows: cardiovascular disease, neurologic disease, or having specific disease process such as infection, tumor, or injury to a specific anatomic structure. This study was approved by the Institutional Review Board of Gachon University.

To measure the hamstring extensibility, the sit and reach test (SRT) was performed using a sitting trunk flexion meter (Sitting Trunk Flexion Meter, TAKEI, Japan). Subjects were seated on the floor with the soles of their feet against the box and with their hips flexed about $90^{\circ}$, and then the flexed hip joints and trunk to reach forward as far as possible with maintaining their knees, arms, and fingers fully extended for approximately $5 \mathrm{~s}^{10)}$. The score was determined as the mean values of 3 consecutive measurements.

To measure pain pressure threshold (PPT), a pressure algometer (NeuroDyneMedicaco Corp., Cambridge, MA, USA) was used. PPT was measured $5 \mathrm{~cm}$ laterally to the L5 spinous process of the side with more pain ${ }^{11)}$. The threshold was determined as the mean values out of 3 consecutive measurements, with a pause of $10 \mathrm{~s}$ between the measurements. Visual analogue scale (VAS) was also used to assess pain levels of subjects ${ }^{12}$.

In the present study, 20 subjects were randomly allocated to the SSD group $(n=10)$ and the control group ( $n=10)$ using a random allocation software. Two groups performed the intervention for $20 \mathrm{~min}$ a day, 3 times a week for a total period of 4 weeks (12 sessions). In the SSD group, bed rest using SSD (Chiropractic nap, Balancecord, Korea) was performed. SSD had $0.5 \mathrm{~cm}$ and $1 \mathrm{~cm}$ processes on the paraspianl muscles for muscle relaxation. The lowest point of SSD was to touch the coccyx in supine position on a hard mat. For SSD application, subjects were maintained in supine position (Fig. 1). The control group performed bed rest only. To confirm whether the subjects performed the intervention in each group, an examiner called each subject once every three days to check the status. For all subjects, SRT, PPT, and VAS were assessed before and after the intervention by the assessor who was blinded to the group assignment.

All statistical analyses were performed using SPSS 18.0. The ratio variables were expressed as the mean \pm standard deviation (SD). Mann-Whitney U test and $\chi^{2}$ test were performed to analyze the general characteristics between the two groups. Wilcoxon signed-ranks test was used to compare the changes before and after the intervention. Mann-Whitney U test was used to compare the changes between the two groups. A p value of less than 0.05 was considered statistically significant.

\section{RESULTS}

The characteristics of participants in the two groups are presented in the Table 1. Prior to the intervention, there were no significant differences in the general characteristics between the two groups. Prior to the intervention, SRT, PPT of SIJ, and VAS also did not show any significant differences between the two groups.

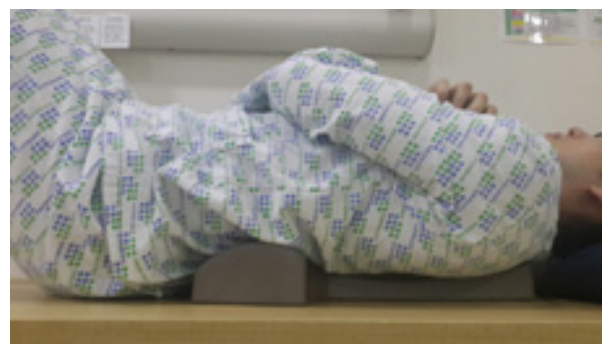

Fig. 1. Spinal support device 
For pain control of SSD, as shown in Table 2, the SSD group significantly increased PPT of SIJ ( $p=0.027$ ) and VAS $(\mathrm{p}=0.005)$, and the control group significantly increased VAS $(\mathrm{p}=0.011)$ before and after the intervention. The SSD group significantly increased VAS $(\mathrm{p}=0.048)$ compared with the control group (Table 3 ). There were no significant differences in PPT between the groups (Table 3). Regarding the changes in hamstring extensibility after SSD intervention, however, both groups did not show a significant improvement in SRT (Table 2). There were no significant differences with respect to SRT between the two groups (Table 3).

\section{DISCUSSION}

This study investigated the effects of SSD on pain and hamstring extensibility in patients with NSLBP by correcting lumbar lordosis in supine position. PPT and VAS was significantly increased in the SSD group. The control group showed a significant improvement in VAS only. The SSD group showed a greater significant improvement of VAS compared with the control group. Thus, we suggest that SSD may be effective for managing NSLBP.

NSLBP is associated with hamstring extensibility and flat back posture. Previous study has reported that back pain is associated with decreased hamstring extensibility ${ }^{13}$. However, we showed that application of SSD for a duration of 4 weeks did not show an increase in hamstring extensibility for patients with NSLBP, both before and after the intervention. SSD is an orthosis that can correct abnormal flat back posture; however, bed-rest with SSD failed to significantly improve hamstring extensibility. Thus, it is difficult to conclude that using SSD increases hamstring extensibility in NSLBP patients.

In this study, the SSD group significantly increased PPT of SIJ for pre-post interventions and significantly increased VAS compared with the control group. This may suggest that best-rest with SSD may be more effective than bed-rest only for patients with NSLBP. The SSD group also showed a significant increase of VAS and PPT compared with the control group. The gate control theory may explain this phenomenon ${ }^{14)}$. Small diameter afferent fibers (A-delta and C fibers) carry pain signals and large diameter afferent fibers (A-alpha and A-beta fibers) carry sensory information (non-painful signal) to the spinal cord, such as vibration and tactile sensation. Gate control theory proposes that a stimulation of large diameter afferent fibers inhibits the neurons in the spinal dorsal horn, preventing pain signals to be transferred by small diameter

Table 1. General characteristics

\begin{tabular}{|c|c|c|}
\hline & SSD group $(n=10)$ & Control group $(n=10)$ \\
\hline Gender (Frmale/Male) & $5 / 5$ & $6 / 4$ \\
\hline Age (years) ${ }^{\mathrm{a}}$ & $31.8 \pm 4.3$ & $30.9 \pm 6.7$ \\
\hline Height $(\mathrm{cm})^{\mathrm{a}}$ & $170.3 \pm 8.8$ & $167.0 \pm 7.8$ \\
\hline Weight $(\mathrm{kg})^{\mathrm{a}}$ & $61.9 \pm 8.2$ & $58.0 \pm 8.8$ \\
\hline
\end{tabular}

${ }^{a}$ Values are expressed as mean $\pm \mathrm{SD}$.

Table 2. Comparisons of pain and extensibility of the hamstrings

\begin{tabular}{lccccccc}
\hline & \multicolumn{2}{c}{ SSD group $(\mathrm{n}=10)$} & \multicolumn{2}{c}{ Control group $(\mathrm{n}=10)$} & & & \\
\cline { 2 - 7 } & \multicolumn{1}{c}{ Pre } & Post & Pre & Post & $\mathrm{p}^{1}$ & $\mathrm{p}^{2}$ & $\mathrm{p}^{3}$ \\
\hline SRT & $-5.15 \pm 2.30$ & $-4.24 \pm 1.66$ & $-5.21 \pm 1.63$ & $-4.67 \pm 1.90$ & 0.970 & 0.241 & 0.689 \\
PTT of SIJ & $6.21 \pm 2.63$ & $7.64 \pm 1.89$ & $6.58 \pm 2.03$ & $7.11 \pm 2.14$ & 0.848 & 0.027 & 0.225 \\
VAS & $5.07 \pm 1.20$ & $3.22 \pm 0.76$ & $4.95 \pm 1.30$ & $3.94 \pm 1.04$ & 0.789 & 0.005 & 0.011 \\
\hline
\end{tabular}

Values are expressed as mean \pm SD. SRT: sit and reach test; PTT of SIJ: pain pressure threshold of sacroiliac joint; VAS: visual analog scale; SSD: spinal support device

$\mathrm{p}^{1}$ : differences at baseline; $\mathrm{p}^{2}$ : pre-post differences for the SSD group; $\mathrm{p}^{3}:=$ pre-post differences for the control group

Table 3. Change score of pain and extensibility of the hamstrings

\begin{tabular}{lccc}
\hline & SSD group $(\mathrm{n}=10)$ & Control group $(\mathrm{n}=10)$ & $\mathrm{p}$ \\
\hline SRT & $0.87 \pm 1.93$ & $0.57 \pm 2.45$ & 0.596 \\
PTT of SIJ & $1.43 \pm 1.87$ & $0.53 \pm 1.34$ & 0.291 \\
VAS & $-1.85 \pm 0.80$ & $-1.01 \pm 0.85$ & 0.048 \\
\hline
\end{tabular}

Values are expressed as mean \pm SD. SRT: sit and reach test; PTT of SIJ: pain pressure threshold of sacroiliac joint; VAS: visual analog scale; SSD: spinal support device 
fibers, whereby a stimulation by non-noxious input can suppress pain signal ${ }^{14)}$. Thus, SSD interventions for 4 weeks may decrease pain via the activation of large nerve fibers stimulated by the SSD process. In addition, considering that NSLBP may result in secondary hyperalgesia, which occurs because of central sensitization in patients with NSLBP, as well as primary hyperalgesia ${ }^{13,15)}$, SSD interventions for 4 weeks may induce changes of the central nervous system, inducing a recovery of central sensitization ${ }^{14,15)}$.

The present study demonstrated that SSD may be effective for pain in patients with NSLBP, suggesting that SSD may be a good therapeutic intervention for NSLBP. However, considering that our study represented data from a small sample size and subjects with mild pain with a short-term intervention of 4 weeks, further studies are necessary to better generalize the effects of SSD for NSLBP patients.

\section{REFERENCES}

1) Maher C, Underwood M, Buchbinder R: Non-specific low back pain. Lancet, 2017, 389: 736-747. [Medline] [CrossRef]

2) O'Sullivan PB, Mitchell T, Bulich P, et al.: The relationship beween posture and back muscle endurance in industrial workers with flexion-related low back pain. Man Ther, 2006, 11: 264-271. [Medline] [CrossRef]

3) Spenkelink CD, Hutten MM, Hermens HJ, et al.: Assessment of activities of daily living with an ambulatory monitoring system: a comparative study in patients with chronic low back pain and nonsymptomatic controls. Clin Rehabil, 2002, 16: 16-26. [Medline] [CrossRef]

4) Halbertsma JP, Göeken LN, Hof AL, et al.: Extensibility and stiffness of the hamstrings in patients with nonspecific low back pain. Arch Phys Med Rehabil, 2001, 82: 232-238. [Medline] [CrossRef]

5) Szeto GP, Lam P: Work-related musculoskeletal disorders in urban bus drivers of Hong Kong. J Occup Rehabil, 2007, 17: 181-198. [Medline] [CrossRef]

6) Hagen KB, Hilde G, Jamtvedt G, et al.: Bed rest for acute low-back pain and sciatica. Cochrane Database Syst Rev, 2004 , (4): CD001254.

7) Nachemson A: Towards a better understanding of low-back pain: a review of the mechanics of the lumbar disc. Rheumatol Rehabil, 1975, 14: 129-143. [Medline] [CrossRef]

8) van Duijvenbode IC, Jellema P, van Poppel MN, et al.: Lumbar supports for prevention and treatment of low back pain. Cochrane Database Syst Rev, 2008, (2): CD001823. [Medline]

9) Oleske DM, Lavender SA, Andersson GB, et al.: Are back supports plus education more effective than education alone in promoting recovery from low back pain?: results from a randomized clinical trial. Spine, 2007, 32: 2050-2057. [Medline] [CrossRef]

10) Miñarro PA, Andújar PS, García PL, et al.: A comparison of the spine posture among several sit-and-reach test protocols. J Sci Med Sport, 2007 , 10: 456-462. [Medline] [CrossRef]

11) Hirayama J, Yamagata M, Ogata S, et al.: Relationship between low-back pain, muscle spasm and pressure pain thresholds in patients with lumbar disc herniation. Eur Spine J, 2006, 15: 41-47. [Medline] [CrossRef]

12) Scott PJ, Huskisson EC: Measurement of functional capacity with visual analogue scales. Rheumatol Rehabil, 1977, 16: 257-259. [Medline] [CrossRef]

13) O’Neill S, Manniche C, Graven-Nielsen T, et al.: Generalized deep-tissue hyperalgesia in patients with chronic low-back pain. Eur J Pain, 2007, 11: 415-420. [Medline] [CrossRef]

14) Woolf CJ: Central sensitization: implications for the diagnosis and treatment of pain. Pain, 2011, 152: S2-S15. [Medline] [CrossRef]

15) Melzack R, Wall PD: Pain mechanisms: a new theory. Science, 1965, 150: 971-979. [Medline] [CrossRef] 